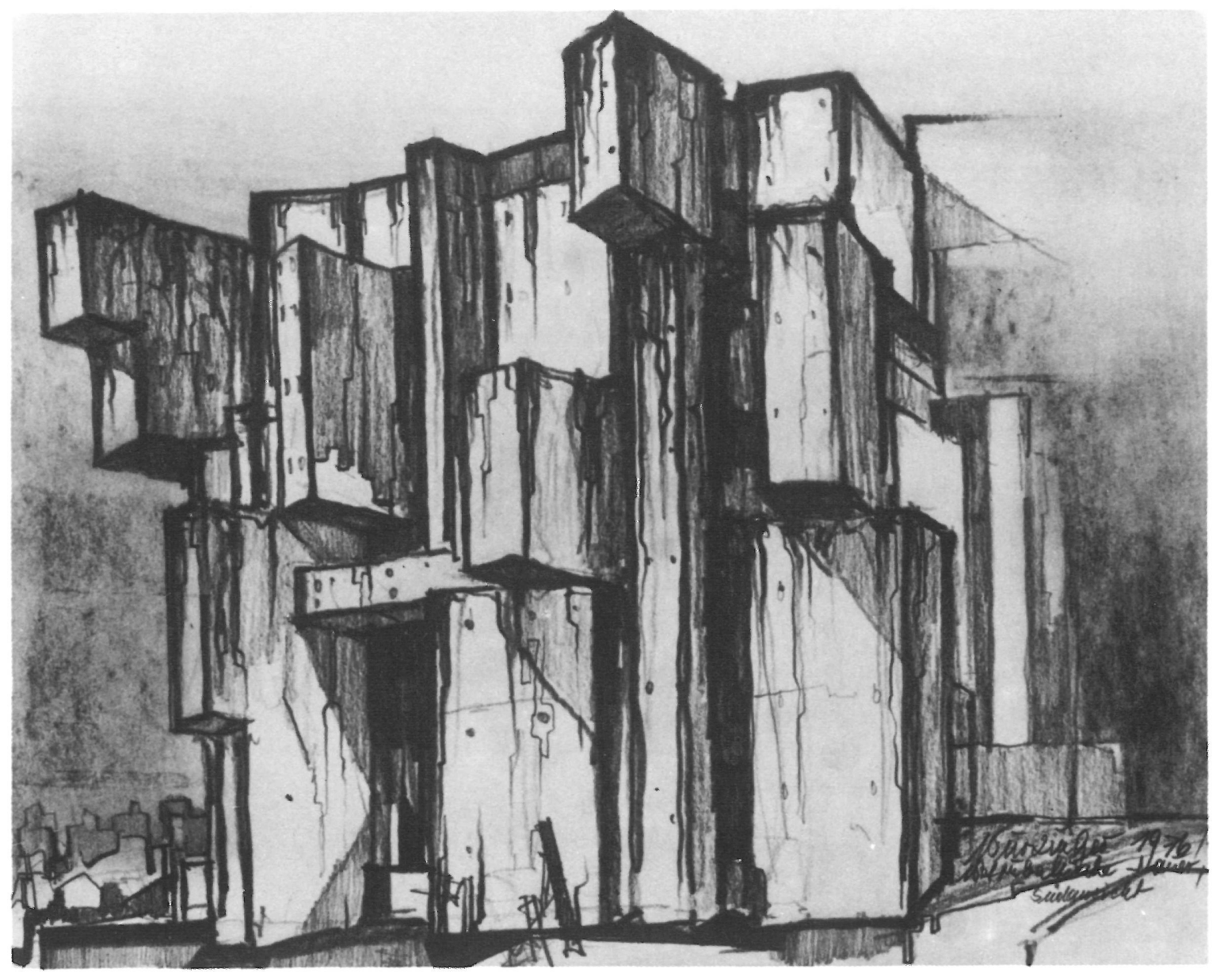

\title{
Iglesia de la Santísima Trinidad en Viena-Austria
}

$148-161$

FRITZ GERHARD MAYR, arquitecto FRITZ WOTRUBA, escultor

sinopsis

\begin{abstract}
La profesión del autor de la iglesia de la Santisima Trinidad queda claramente reflejada en su obra, una de las realizaciones religiosas austríacas más interesantes.

Su carácter de escultor no le impone condicionantes técnicos o sociales, por el contrario, le deja libre para buscar el sentido religíoso por los medios más distintos. Así, mediante 152 bloques de diferentes tamaños y formas configura un diversificado volumen escultórico en el que distribuye los locales parroquiales y la íglesia propiamente dicha. Estos bloques, alternando con las variadas superficies acristaladas, contribuyen a crear en el interior el ambiente de recogimiento tan necesario en este tipo de taladas, contribuy
\end{abstract}

La iglesia de la Santísima Trinidad, considerada como una de las edificaciones religiosas más interesantes de Austria, se empezó a construir según el proyecto del escultor Fritz Wotruba, terminándose después de su muerte.

La profesión del autor queda perfectamente reflejada en la obra pues, como él mismo dijo, se sentía libre de ciertos prejuicios a los que están sometidos los técnicos: «No me interesa ni la arquitectura social o comunal ni la individual. No me preocupa la estética. Lo que me fascina es la arquitectura que se construye libremente, sin ligaduras, sin barreras, sólo siguiendo la idea concebida.» 


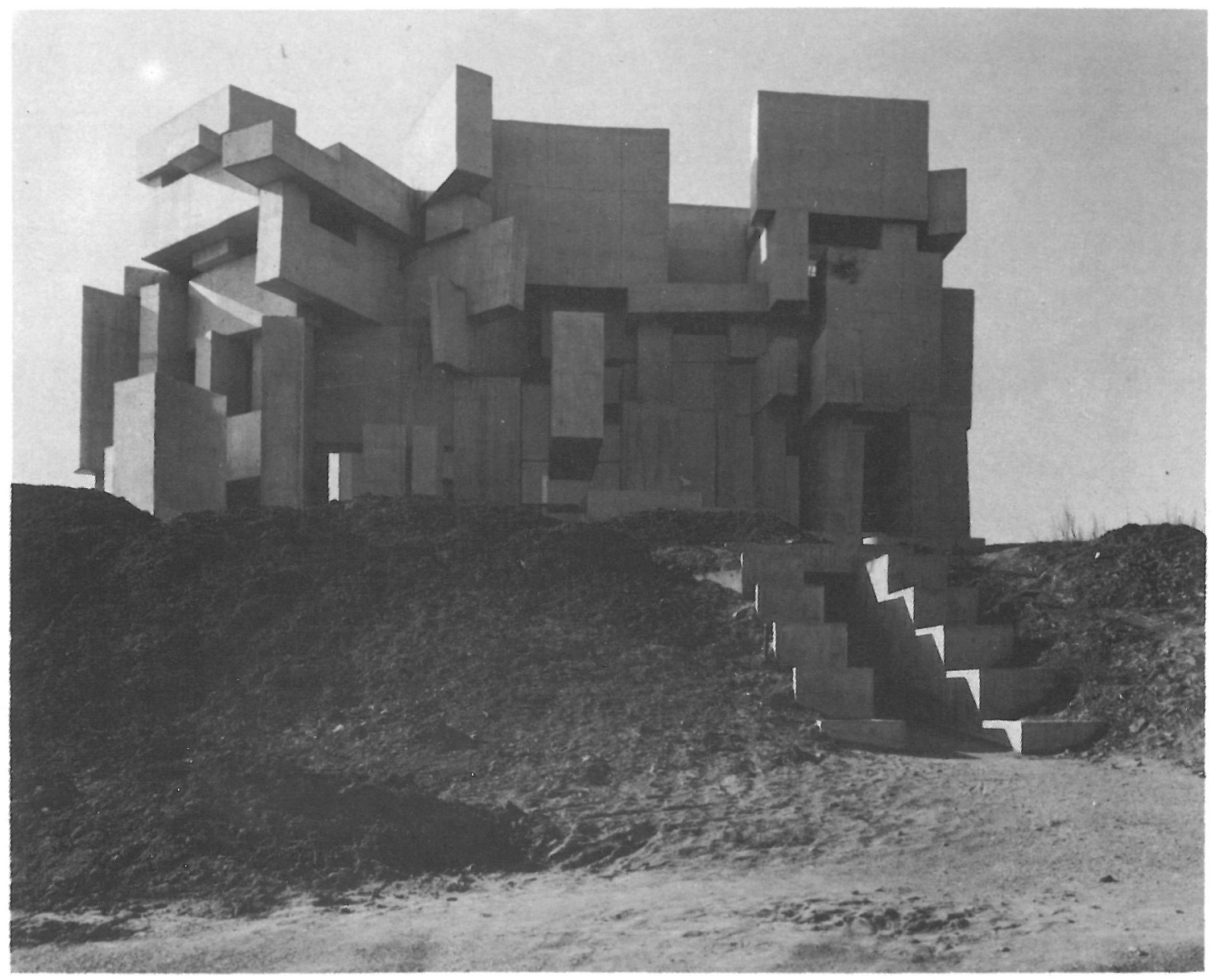

Para él la única y pura realidad fue: "Una orden dedicada a las plegarias necesita un alojamiento. Así como para el cuerpo hay una casa, la oración precisa un templo. De esta forma lo que parece inútil puede convertirse en algo con sentido; y lo que tiene sentido en algo de gran provecho."

Partiendo de estas premisas fabricó originalmente, junto con el arquitecto Fritz Gerhard Mayr, unos modelos de yeso sin escala para, a partir de ellos, llegar a una maqueta en madera. Sobre esta última se determinó la escala, se midieron los distintos bloques, plasmados en el proyecto en siete niveles distintos, y se elaboraron los planos.

El proyecto finalmente realizado consta, en rasgos generales, de una planta baja de unos $340 \mathrm{~m}^{2}$, y una planta alta de $285 \mathrm{~m}^{2}$ de superficie útil.

El nivel inferior alberga una sala parroquial, con escenario para distintos acontecimientos sociales y religiosos, y capacidad para 100 personas aproximadamente. Además se han previsto toda una serie de locales necesarios destinados a lograr el correcto funcionamiento de la parroquia, tales como salas de grupos y de juntas, archivo, sacristía, etc. Esta planta baja no tiene ventanas, por lo que se la dispuso completamente climatizada. 
El nivel superior, que aloja el templo propiamente dicho, presenta una planta configurada como un polígono irregular. Con su longitud de $30 \mathrm{~m}$ y su anchura máxima de $22 \mathrm{~m}$, ofrece superficie suficiente para dar cabida a 300 fieles. El espacio interior lo conforman 152 bloques de muy distintos tamaños y formas, pues van desde los 0,8 a los $64 \mathrm{~m}^{3}$. Dichos bloques se unen entre sí mediante paramentos acristalados con vidrio aislante, y se rematan superiormente con una cubierta plana a base de una placa de hormigón debidamente aislada e impermeabilizada.

W. SCHMIDT

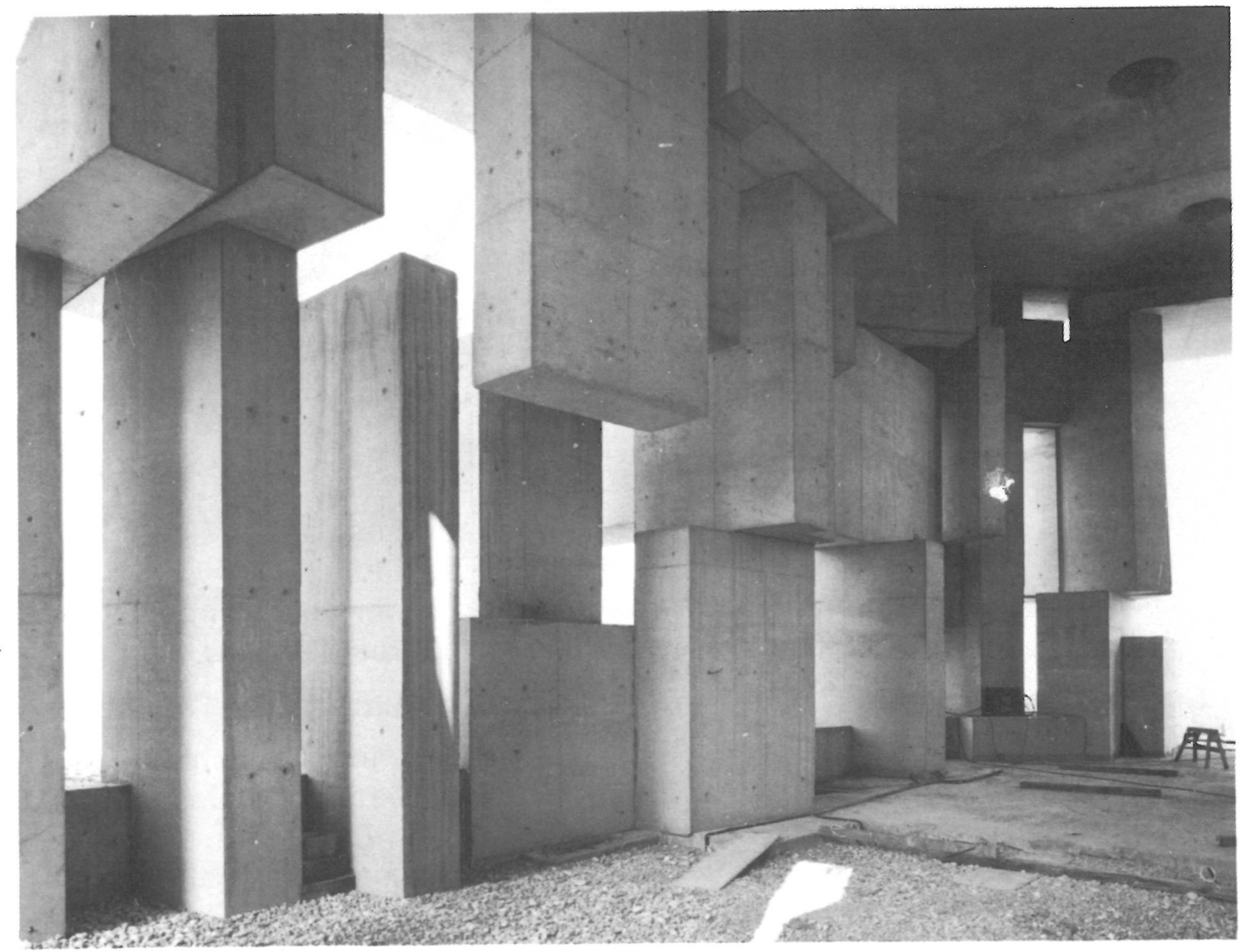

Fotos: Werkfoto.

\section{résumé}

Eglise de la Très Sainte Trinité. Vienne - Austriche

Fritz Gerhard Mayr, architecte

Fritz Wotruba, escupteur

La profession de l'auteur de l'église de la Très Sainte Trinité se reflète clairement dans son œuvre, une des réalisations religieuses autrichiennes des plus intéressantes.

Son caractère de sculpteur ne lui impose aucun conditionnement technique ou social, au contraire, il le laisse libre de rechercher un sens religieux par les moyens les plus distincts. Ainsi, à l'aide de 152 blocs de différentes tailles et formes it blocs de differentes tailles et formes compose un volume sculptural diversifie dans lequel il distribut les locaux de la pa-
roisse et de l'église proprement dite. Ces blocs, alternant avec les différentes superficies vitrées, contribuent à créer à l'intérieur cette ambiance recueillement si nécessaire pour ce type d'édifice.

\section{summary}

Holy Trinity Church in Vienna, Austria

Fritz Gerhard Mayr - Architect Fritz Wotruba - Sculptor

The profession of the designer of the Holy Trinity Church is clearly reflected in this work, one of the most interesting Austrian religious buildings.

His sculptor trade does not impose on him any technical or social condition, but rather, affords him the necessary freedom to search for religious feeling through the most varied means and media. Thus, using 152 blocks of different sizes and shapes, he constructs a diversified sculptoric volume where the parrochial facilities and the church proper are housed. These blocks, alternating with glazed surfaces, help to create inside a feeling of quiet seclusion so necessary in this type of buildings.

\section{zusammenfassung}

\section{Dreieinigkeitskirche \\ Wien - Oesterreich}

\section{Architekt: Fritz Gerhard Mayr} Bildhauer: Fritz Wotruba

Der Beruf des Autors der Dreieinigkeitskirche spiegelt sich klar in seinem Werk wider, wobei es sich um einen der interesessantesten religiösen Bauten osterreichs handelt.

In seiner Eigenschaft als Bildhauer unterliegt er keinen technischen oder sozialen Bedingungen, ganz im Gegenteil, er ist frei, den religiösen Sinn mit den verschiedenartigsten Mitteln auszudrücken. So bildet er aus 152 Blöcken unterschiedlicher Grösse und Form ein manniffaltiges Skulpturvolumen, welches die Kirchenräume und die eigentliche Kirche enthält. In Awechslung mit verschiedenen verglasten Flächen tragen diese Blöcke dazu bei, im Innenraum die für diese Bauten so erforderliche andächtige Stimmung zu schaffen. 